\title{
Homogenized century-long surface incident solar radiation over Japan
}

\author{
Qian Ma, Kaicun Wang, Yanyi He, Liangyuan Su, Qizhong Wu, Han Liu, and Youren Zhang \\ State Key Laboratory of Earth Surface Processes and Resource Ecology, College of Global Change and Earth \\ System Science, Beijing Normal University, Beijing 100875, China \\ Correspondence: Kaicun Wang (kcwang@bnu.edu.cn)
}

Received: 6 July 2021 - Discussion started: 23 August 2021

Revised: 17 December 2021 - Accepted: 19 December 2021 - Published: 4 February 2022

\begin{abstract}
Surface incident solar radiation $\left(R_{\mathrm{S}}\right)$ plays a key role in climate change on Earth. $R_{\mathrm{S}}$ can be directly measured, and it shows substantial variability on decadal scales, i.e. global dimming and brightening. $R_{\mathrm{S}}$ can also be derived from the observed sunshine duration (SunDu) with reliable accuracy. The SunDu-derived $R_{\mathrm{S}}$ has been used as a reference to detect and adjust inhomogeneity in the observed $R_{\mathrm{S}}$. However, both the observed $R_{\mathrm{S}}$ and SunDu-derived $R_{\mathrm{S}}$ may have inhomogeneity. In Japan, SunDu has been measured since 1890 , and $R_{\mathrm{S}}$ has been measured since 1961 at $\sim 100$ stations. In this study, the observed $R_{\mathrm{S}}$ and SunDu-derived $R_{\mathrm{S}}$ were first checked for inhomogeneity independently using the statistical software RHtests. If confirmed by the metadata of these observations, the detected inhomogeneity was adjusted based on the RHtests quantile-matching method. Second, the two homogenized time series were compared to detect further possible inhomogeneity. If confirmed by the independent ground-based manual observations of cloud cover fraction, the detected inhomogeneity was adjusted based on the reference dataset. As a result, a sharp decrease of more than $20 \mathrm{~W} \mathrm{~m}^{-2}$ in the observed $R_{\mathrm{S}}$ from 1961 to 1975 caused by instrument displacement was detected and adjusted. Similarly, a decline of about $20 \mathrm{~W} \mathrm{~m}^{-2}$ in SunDu-derived $R_{\mathrm{S}}$ due to steady instrument replacement from 1985 to 1990 was detected and adjusted too. After homogenization, the two estimates of $R_{\mathrm{S}}$ agree well. The homogenized SunDu-derived $R_{\mathrm{S}}$ show an increased at a rate of $0.9 \mathrm{~W} \mathrm{~m}^{-2}$ per decade $(p<0.01)$ from 1961 to 2014 , which was caused by a positive aerosol-related radiative effect $\left(2.2 \mathrm{~W} \mathrm{~m}^{-2}\right.$ per decade) and a negative cloud cover radiative effect $\left(-1.4 \mathrm{~W} \mathrm{~m}^{-2}\right.$ per decade). The brightening over Japan was the strongest in spring, likely due to a significant decline in aerosol transported from Asian dust storms. The observed raw $R_{\mathrm{S}}$ data and their homogenized time series used in this study are available at https://doi.org/10.11888/Meteoro.tpdc.271524 (Ma et al., 2021).
\end{abstract}

1

Surface incident solar radiation $\left(R_{\mathrm{S}}\right)$ plays a vital role in atmospheric circulation, hydrologic cycling, and ecological equilibrium; therefore, its decrease and increase, termed global dimming and brightening (Wild et al., 2005; Shi et al., 2008), have received widespread interest from the public and scientific community (Allen et al., 2013; Xia, 2010; Wang et al., 2013; Tanaka et al., 2016; Ohmura, 2009; He et al., 2018). In addition, the impact factors such as clouds and aerosols on the variation in $R_{\mathrm{S}}$ have been widely studied (Wild et al., 2021; Qian et al., 2006; Feng and Wang, 2021a).
Ground-based observations of $R_{\mathrm{S}}$ are the first recommendation for detecting global dimming and brightening. However, observational data may be inevitably ruined by artificial shifts, which my lead to the variability in $R_{\mathrm{S}}$ with large uncertainties. Wang et al. (2015) point out that instrument replacements and the reconstruction of the observational network introduced substantial inhomogeneity into the time series of observed $R_{\mathrm{S}}$ over China for 1990-1993. Manara et al. (2016) also show the instrument changes from the Robitzsch pyranometer to the Kipp \& Zonen CM11 pyranometer before 1980 caused no clear dimming in Italy. Until recently, Wild et al. (2021) use a well-maintained data series at a site 
in Germany with long time duration to investigate the dimming and brightening in central Europe under clear-sky conditions and point out that the aerosol pollutants are likely major drivers in the $R_{\mathrm{S}}$ variations. Augustine and Hodges (2021) use Surface Radiation Budget (SURFRAD) Network observations to explore the variability in $R_{\mathrm{S}}$ over the US from 1996 to 2019 and find that cloud fraction can explain $62 \%$ of the variation of $R_{\mathrm{s}}$, while aerosol optical depth (AOD) only accounts for $3 \%$. Both studies also indicate the measurement instruments have been changed over the observational time periods, which may introduce non-climatic shifts and inhomogeneity in the raw data series.

Homogenizing the observed $R_{\mathrm{S}}$ has been attempted in China (Wang et al., 2015; Tang et al., 2011; Yang et al., 2018), Italy (Manara et al., 2016), Spain (SanchezLorenzo et al., 2013), and Europe (Sanchez-Lorenzo et al., 2015). It is essential to find a homogeneous reference station to compare with the possible inhomogeneous station to test and adjust the inhomogeneity in the observed time series, as done for the homogenization of air temperature (Du et al., 2020; Zhou et al., 2021). However, this process is difficult for $R_{\mathrm{S}}$ because the instrument replacement of $R_{\mathrm{S}}$ generally occurs nearly simultaneously throughout a country. Therefore, the sunshine-duration-derived (SunDuderived) $R_{\mathrm{S}}$ (Yang et al., 2006) has been used as a homogeneous reference dataset to detect and adjust the inhomogeneity in $R_{\mathrm{S}}$ in China (Wang et al., 2015).

SunDu records the hours of surface direct solar radiation exceeding $120 \mathrm{~W} \mathrm{~m}^{-2}$ and provides an alternative way to estimate $R_{\mathrm{s}}$ (Yang et al., 2006; Stanhill and Cohen, 2008). SunDu-derived $R_{\mathrm{S}}$ is capable of capturing the variability in $R_{\mathrm{S}}$. He et al. (2018) use the SunDu-derived $R_{\mathrm{S}}$ at $\sim 2600$ stations to revisit the global dimming and brightening over different continents and restate the dimming over China and Europe is consistent with the increasing trend of clouds and aerosols. Feng and Wang (2021a, b) merge the satellite retrievals with SunDu-derived $R_{\mathrm{S}}$ to produce high-resolution long-term solar radiation over China and indicate the cloud fraction could explain approximately $86 \%-97 \%$ of $R_{\mathrm{S}}$ variation. Zeng et al. (2020) demonstrate that SunDu plays a dominant role in determining $R_{\mathrm{S}}$ based on a random forest model framework across China. Stanhill and Cohen (2005) indicate the high correlation between SunDu and $R_{\mathrm{S}}$ at the 26 stations in the United States. Sanchez-Lorenzo et al. (2008) show the variation in SunDu is consistent with that in $R_{\mathrm{S}}$ over western Europe for 1938-2004 and the SunDu time evolution in spring can partly be explained by clouds and that in winter can be related to the anthropogenic aerosol emissions. Stanhill and Cohen (2008) establish a simple linear relationship between $R_{\mathrm{S}}$ and SunDu to determine the long-term variation in $R_{\mathrm{S}}$ over Japan. Manara et al. (2017) highlight that atmospheric turbidity should be considered when using SunDu for investigating multidecadal evolution of $R_{\mathrm{S}}$.

Artificial shifts in SunDu observations may come from the replacement of instruments. It has been revealed that the
Jordan recorder is $10 \%$ more sensitive than the CampbellStokes recorder for SunDu measurements (Noguchi, 1981). The homogenization of SunDu has been carried out in the Iberian Peninsula (Sanchez-Lorenzo et al., 2007), Switzerland (Sanchez-Lorenzo and Wild, 2012), and Italy (Manara et al., 2015).

The measurement of $R_{\mathrm{S}}$, which started in 1961 in Japan, has a long history (Tanaka et al., 2016), and a data record of more than half a century has been accumulated. The dataset has been widely used to study decadal variability (Wild et al., 2005; Stanhill and Cohen, 2008) and to evaluate model simulations (Allen et al., 2013; Dwyer et al., 2010). The Eppley and Robitzsch pyranometers used to measure $R_{\mathrm{S}}$ over Japan were replaced by the Moll-Gorczynski thermopile pyranometers in the early 1970s (Tanaka et al., 2016). However, the possible inhomogeneity of the observed $R_{\mathrm{S}}$ over Japan has not been well quantified, and most existing studies directly used raw $R_{\mathrm{S}}$ data (Wild et al., 2005; Tanaka et al., 2016; Tsutsumi and Murakami, 2012; Allen et al., 2013; Wild and Schmucki, 2011; Kudo et al., 2012; Ohmura, 2009). Some studies have had to abandon data from the early years and focused on only $R_{\mathrm{S}}$ data collected after 1975 (Tsutsumi and Murakami, 2012; Dwyer et al., 2010). Therefore, the observed decadal variability in $R_{\mathrm{S}}$ over Japan is questionable, especially for the 1961-1975 time period.

In Japan, SunDu observations started in 1890, and more than a century of data have been recorded. They cannot be too precious for the climate change detection on a century scale. It is reported that the Jordan recorders used to measure SunDu were replaced by EKO rotating-mirror recorders in approximately 1986 (Inoue and Matsumoto, 2003; Stanhill and Cohen, 2008). Therefore, SunDu observations over Japan themselves may suffer inhomogeneity issues.

Non-climatic shifts in the observations may severely influence the climate assessment; therefore rigorous homogenization is required. The World Meteorological Organization (WMO) guidelines on climate metadata and homogenization list 14 data homogenization assessment techniques developed and applied by different groups/authors (Aguilar et al., 2003). Reeves et al. (2007) compared eight representative homogenization methods and provided guidelines for which procedures work best in different situations; for example the standard normal homogeneity (SNH) test (Alexandersson, 1986) works best if good reference series are available, and two-phase regressions of the Wang procedure (Wang, 2003) are optimal for an unavailable condition of good reference series. Based on the comparison work, the RHtests method was improved by detecting multiple change points in the climate data no matter if the reference series are available (Wang, 2008b; Wang et al., 2010, 2007; Wang, 2008a). This method, which first detects the change points in a series using penalized maximal tests and then tunes the inhomogeneous data segments to be consistent with other segments in empirical distributions, has been widely used in homogeniz- 
ing climate variables (Dai et al., 2011; Wang et al., 2010; Du et al., 2020; Zhou et al., 2021).

Discontinuities inevitably occurred in the long-term observation system which are required to be checked out and adjusted in the raw data. The homogenized series pose a significant role in the realistic and reliable assessment of climate trend and variability. The main objective of this study is to detect and adjust the inhomogeneity in $R_{\mathrm{S}}$ estimates over Japan. The metadata were first extracted from website information and related records at each site. The SunDu observations were converted into $R_{\mathrm{S}}$. The RHtests method was applied to homogenize the observed $R_{\mathrm{S}}$ and SunDu-derived $R_{\mathrm{S}}$, and finally, the century-long homogenized $R_{\mathrm{S}}$ data were produced over Japan. Furthermore, the impacts of cloud cover and aerosols on $R_{\mathrm{S}}$ variation over Japan in recent decades were explored.

\section{Data and methods}

\subsection{Surface incident solar radiation and sunshine duration}

The monthly observed $R_{\mathrm{S}}$ at 105 stations and SunDu at 156 stations were downloaded from the Japan Meteorology Agency (JMA) website (see Table S1 in the Supplement and Fig. 1). $R_{\mathrm{S}}$ records were available from 1961. During the 1960 s, two $R_{\mathrm{S}}$ measurements were conducted in parallel by both Eppley and Robitzsch pyranometers. In the early 1970s (see Fig. 2 and Table S2), these instruments were replaced by Moll-Gorczynski thermopile pyranometers. This replacement occurred at approximately $12.4 \%$ of $R_{\mathrm{S}}$ stations in 1971 , followed by $22.9 \%, 24.8 \%, 3.8 \%$, and $30.5 \%$ in the next 4 years, which may have caused severe data discontinuity problems (Tanaka et al., 2016).

SunDu has been routinely measured since 1890 . Jordan recorders were replaced by EKO rotating-mirror recorders at $49.4 \%$ of SunDu stations in 1986. Until 1990, nearly all of the SunDu stations used new instruments for observations; $4.5 \%$ of SunDu stations before 1985 and $9.0 \%$ of SunDu stations after 2000 were moved away from the original sites (see Fig. 2 and Table S2) (Stanhill and Cohen, 2008).

In this study, SunDu was used to derive $R_{\mathrm{S}}$ based on the following equation (Yang et al., 2006):

$R_{\mathrm{S}} / R_{\mathrm{c}}=a_{0}+a_{1} \cdot n / N+a_{2} \cdot(n / N)^{2}$,

where $n$ is sunshine duration hours; $N$ is the maximum possible sunshine duration; $R_{\mathrm{c}}$ is surface solar radiation under clear skies; and $a_{0}, a_{1}$, and $a_{2}$ are coefficients. This method was recommended in many studies (Wang et al., 2015; Tang et al., 2011).

\subsection{Homogenization method}

Both $R_{\mathrm{S}}$ and SunDu measurements over Japan suffer severe inhomogeneity problems, which require rigorous data homogenization. RHtests (http://etccdi.pacificclimate. org/software.shtml, last access: 21 January 2022) is a widely used method to detect and adjust multiple change points in a climate data series, such as in surface temperature (Du et al., 2020), radiosonde temperature (Zhou et al., 2021), precipitation (Wang et al., 2010), and surface incident solar radiation (Yang et al., 2018). RHtests provides two algorithms, the penalized maximal $t$ (PMT) test (Wang et al., 2007) and the penalized maximal $F$ (PMF) test (Wang, 2008b), to detect change points. The problem of lag-1 autocorrelation in detecting mean shifts in time series was also resolved (Wang, 2008a). The PMT algorithm requires the base time series to have no trend, and hence a reference series is needed. It is invalid when a reference series is not often available or its homogeneity is not sure; also the trend in the base and reference series are probably different. The PMF algorithm allows the time series to be in a constant trend and thus is applicable without a reference series. Both algorithms have higher detection power, and the false-alarm rate can be reduced by an empirically constructed penalty function.

As the instrument changes for $R_{\mathrm{S}}$ and SunDu observation happened nearly nationwide and simultaneously, it is difficult to find reference data series to match the base data series, and hence the PMF algorithm was used to detect the change points in this study. Multiple change points were detected including climate signals and artificial shifts, and only the ones confirmed by discontinuity information from metadata in Table S2 were left to be adjusted. Then two homogenized series based on the direct measurement of $R_{\mathrm{S}}$ and SunDuderived $R_{\mathrm{S}}$ were obtained.

Large uncertainties may still exist in both homogenized data series, as the discontinuities in the raw observations may not be sufficiently and correctly recorded in the metadata. Further change points can be detected by considering the impact of the variation in independent climate variables such as clouds and aerosols on the $R_{\mathrm{S}}$ variation. If these uncertainties were found, further change point detections were needed based on the PMT or PMF algorithm.

To diminish all significant artificial shifts caused by the change points, newly developed quantile-matching (QM) adjustments in RHtests (Vincent et al., 2012; Wang et al., 2010) were performed to adjust the series so that the empirical distributions of all segments of the detrended base series agree with each other. The corrected values are all based on the empirical frequency of the datum to be adjusted.

Another independent homogenization method proposed by Katsuyama (1987), which was developed due to the replacement of the Jordan recorders with EKO rotatingmirror recorders during the late 1980s, is denoted as follows:

$$
S_{\mathrm{R}}=0.8 S_{\mathrm{J}}\left(S_{\mathrm{J}}<2.5 \mathrm{hd}^{-1}\right),
$$



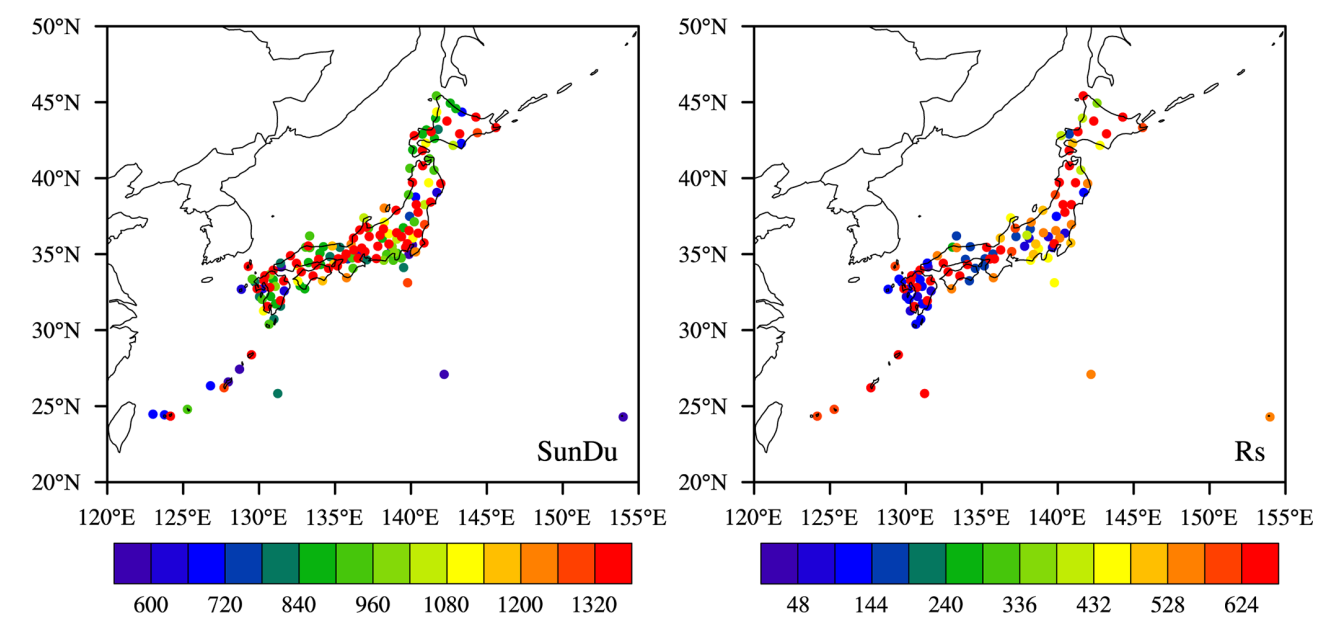

Figure 1. The spatial distribution of stations over Japan with observed sunshine duration (SunDu, 156 stations) and surface incident solar radiation $\left(R_{\mathrm{S}}, 105\right.$ stations) data. The colours indicate the data length of the SunDu records from 1890 to 2015 and $R_{\mathrm{S}}$ records from 1961 to 2015. Unit: month.

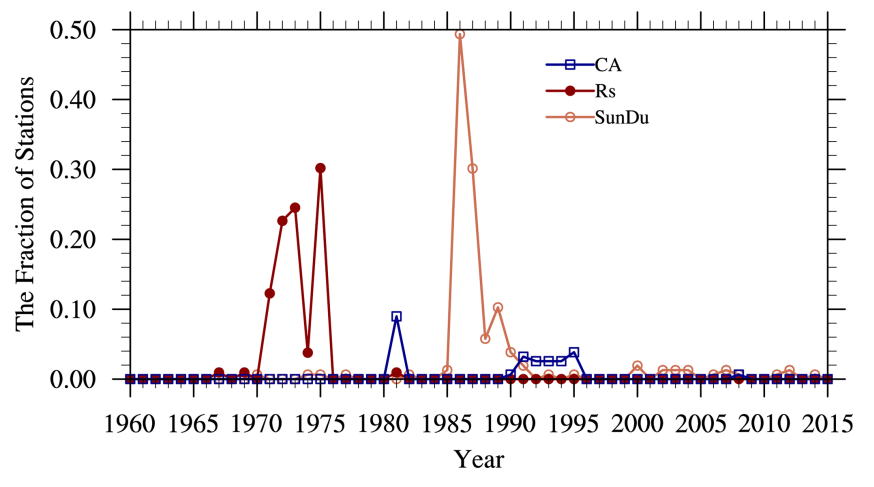

Figure 2. The fraction of stations that suffer from data inhomogeneity due to site relocation, the change of instruments, and the measurement method for sunshine duration (SunDu) records, cloud amount (CA) records, and surface incident solar radiation $\left(R_{\mathrm{S}}\right)$ records. In total, there were 156 stations with SunDu records, 105 of which had $R_{\mathrm{S}}$ records and 155 of which had CA records. The inhomogeneity information shown here was derived from metadata from https://www.data.jma.go.jp/obd/stats/data/en/smp/index. html (last access: 21 January 2022) and was used as primary information to perform the inhomogeneity adjustment in the RHtests method detailed in Sect. 2.2.

$S_{\mathrm{R}}=S_{\mathrm{J}}-0.5\left(S_{\mathrm{J}} \geq 2.5 \mathrm{hd}^{-1}\right)$,

where $S_{\mathrm{J}}$ is the daily SunDu observed by the Jordan recorders before replacement and $S_{\mathrm{R}}$ is the daily SunDu adjusted to be consistent with the values observed with the EKO rotatingmirror recorders.

These two homogenization methods were compared in this study and yielded nearly the same SunDu-derived $R_{\mathrm{S}}$ variation, as shown in Fig. 3. Although the second method proposed by Katsuyama (1987) is simple and efficient, we just

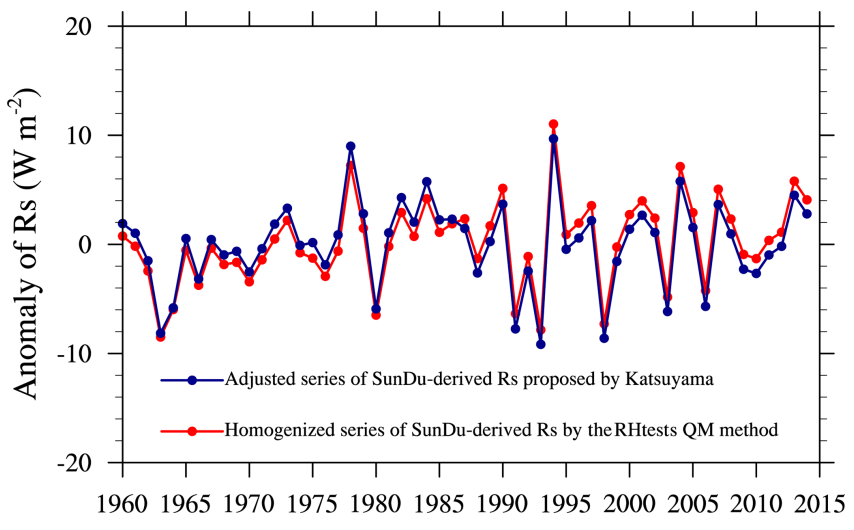

Figure 3. The anomalies of surface incident solar radiation $\left(R_{\mathrm{S}}\right)$ derived from homogenized sunshine duration (SunDu) data (red line) by the RHtests QM method and other independent data (blue line) adjusted by the method in Katsuyama (1987). Both of the homogenized datasets yield nearly the same $R_{\mathrm{S}}$ variation.

use it to cross-validate the accuracy of the RHtests method. Since most artificial shifts in the observation system were undocumented worldwide, the statistical methods including RHtests are optimal to identify these non-climatic signals and reduce the discontinuities in the data series. As RHtests can detect the change points in the raw data series when the metadata are unavailable, while Katsuyama (1987) cannot, RHtests was selected in this study.

\subsection{Clouds}

Clouds play an important role in $R_{\mathrm{S}}$ variation (Norris and Wild, 2009). Monthly cloud cover observations at 155 stations were also available on the JMA website. The observation time for cloud amount has been 08:00-19:00 LT since 
1981 at $9.0 \%$ of cloud amount stations and 08:30-17:00 LT from 1990 to 1995 at another $15.4 \%$ of cloud amount stations (see Fig. 2 and Table S2). However, the difference between annual raw and homogenized cloud data is trivial, as cloud data are relatively homogeneous in space compared with $R_{\mathrm{S}}$ and SunDu observations. A site observation of cloud amount can represent the value over a large spatial scale, likely leading to a few inhomogeneity issues for cloud data.

To explore the impact of the cloud cover anomaly on the $R_{\mathrm{S}}$ variation, the cloud cover radiative effect (CCRE), defined as the change in $R_{\mathrm{S}}$ produced by a change in cloud cover, was proposed by the following (Norris and Wild, 2009):

$$
\begin{aligned}
& \left.\left.\mathrm{CCRE}^{\prime} \text { (lat, long, } y, m\right)=\mathrm{CC}^{\prime} \text { (lat, long, } y, m\right) \\
& \times \mathrm{CRE} \text { (lat, long, } m) / \overline{\mathrm{CC}}(\text { lat, long, } m),
\end{aligned}
$$

where lat is the latitude, long is the longitude, $y$ is the year, $m$ is the month, $\mathrm{CCRE}^{\prime}$ is the cloud cover radiative effect anomaly, $\mathrm{CC}^{\prime}$ is the cloud cover anomaly, $\overline{\mathrm{CC}}$ is the climatology of cloud cover in 12 months, and CRE is the cloud radiative effect calculated by the $R_{\mathrm{S}}$ difference under all-sky and clear-sky conditions.

The residual radiative effect was determined by removing the CCRE anomalies from the $R_{\mathrm{S}}$ anomalies. It is noted that a part of the cloud albedo radiative effect proportional to the cloud amount was contained in the CCRE, as a large cloud amount tends to yield enhanced cloud albedo, whereas another part of the cloud albedo radiative effect due to the aerosol first indirect effect (more aerosols facilitating more cloud condensation nuclei may enhance cloud albedo) may be included in the residual radiative effect, which mainly contains the aerosol radiative effect.

Clouds and the Earth's Radiant Energy System (CERES) provides a reliable surface incident solar radiation (Ma et al., 2015) primarily based on the Moderate Resolution Imaging Spectroradiometer (MODIS) cloud and aerosol products (Kato et al., 2012). The cloud amount in CERES agrees well with the observations, and the annual CRE in CERES is well correlated with the annual cloud amount in Fig. 10. The regional average cloud amount over Japan in Fig. 10 (blue line) increases at a rate of $0.7 \%$ per decade from 1960 to 2015, which is consistent with the previous results (Fig. 4 in Tsutsumi and Murakami, 2012).

In this study, long-term observations of cloud amount and monthly cloud radiative effect (CRE) data in the CERES EBAF (Energy Balanced and Filled) edition were used following Eq. (4) to distinguish the cloud cover radiative effect from $R_{\mathrm{S}}$ variation.

\subsection{Data processing}

We first interpolated the monthly observational data at sites into $1^{\circ} \times 1^{\circ}$ grid data and then calculated the area average of the climate variables. As the brightening and dimming over Japan were the main concern in this study, monthly values were converted into annual values for calculation. If there are missing values in any month in a specific year, the annual value for that year is set to a missing value. The linear regression was used for trend calculation.

\section{Results}

In this section, we first compared the observed $R_{\mathrm{S}}$ and sunshine-duration-derived $R_{\mathrm{S}}$ before and after adjustment to demonstrate the necessity and feasibility of the homogenization procedure in Sect. 3.1. As artificial shifts may not be sufficiently and correctly documented by metadata, uncertainties may still exist in the homogenized series. We then tried to explore these uncertainties by considering the influence of other independent climate variables such as clouds and aerosols on the $R_{\mathrm{S}}$ variation and ultimately created a more reasonable homogenized $R_{\mathrm{s}}$ series in Sect. 3.2. In Sect. 3.3, we claimed the significant correction in trend analysis of $R_{\mathrm{S}}$ in Japan and quantified the influence of clouds and aerosols on the $R_{\mathrm{s}}$ variation.

\subsection{Homogenization of observed $R_{\mathrm{S}}$ and sunshine-duration-derived $R_{\mathrm{S}}$}

The comparisons between raw data and homogenized data at each site were shown in Fig. 4, and their differences were illustrated in Fig. 5. Compared with raw data, the absolute values of biases between $R_{\mathrm{S}}$ and SunDu-derived $R_{\mathrm{S}}$ at 74 stations decrease after homogenization, of which the absolute values of biases decrease by more than $4 \mathrm{~W} \mathrm{~m}^{-2}$ at 42 stations and more than $10 \mathrm{~W} \mathrm{~m}^{-2}$ at 8 stations. The root mean square errors at 80 stations were reduced after homogenization, of which reductions are more than $4 \mathrm{~W} \mathrm{~m}^{-2}$ at 40 stations. After adjustments, the correlation coefficients between the annual observed $R_{\mathrm{S}}$ and annual SunDu-derived $R_{\mathrm{S}}$ are improved at 68 stations, including an improvement of more than 0.2 at 31 stations. There are 41 stations (marked with red in Table S1, Fig. 6) at which the correlation coefficients were greater than 0.5 , and the biases and the root mean square errors generally decrease after homogenization.

Figure 7, as an example, shows the time series of surface incident solar radiation ( $R_{\mathrm{S}}$ and SunDu-derived $R_{\mathrm{S}}$ ) at the Hamada site (WMO ID: 47755; lat 34.9, long 132.07) before and after homogenization. Details in the improvements after homogenization at most stations can be traced back to Figs. 4, 5, and 6. The improved patterns of time series of surface incident solar radiation after homogenization highlight the necessity and feasibility of the RHtests method. The SunDu-derived $R_{\mathrm{s}}$ variation over Japan during recent decades inferred from these "perfect" data at 41 sites (Fig. 8) was nearly identical to that from all available data at 156 sites (as shown in Table 1 and Fig. 9). 


\section{Before Homogenization}
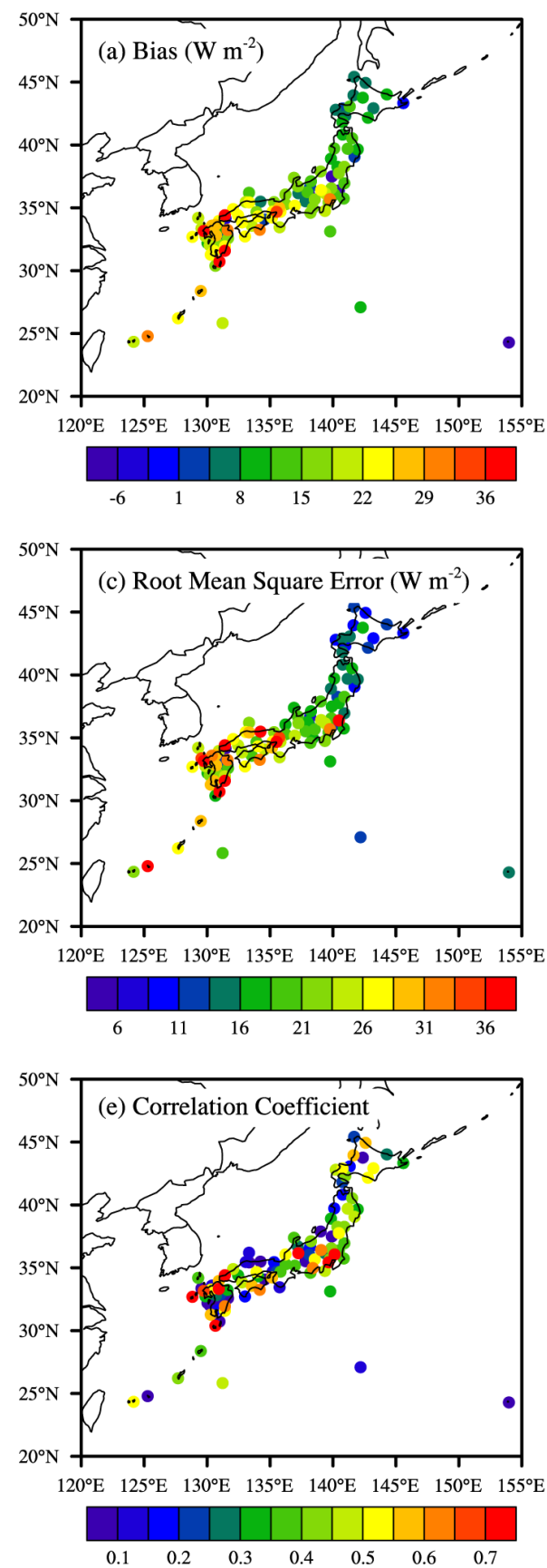

After Homogenization
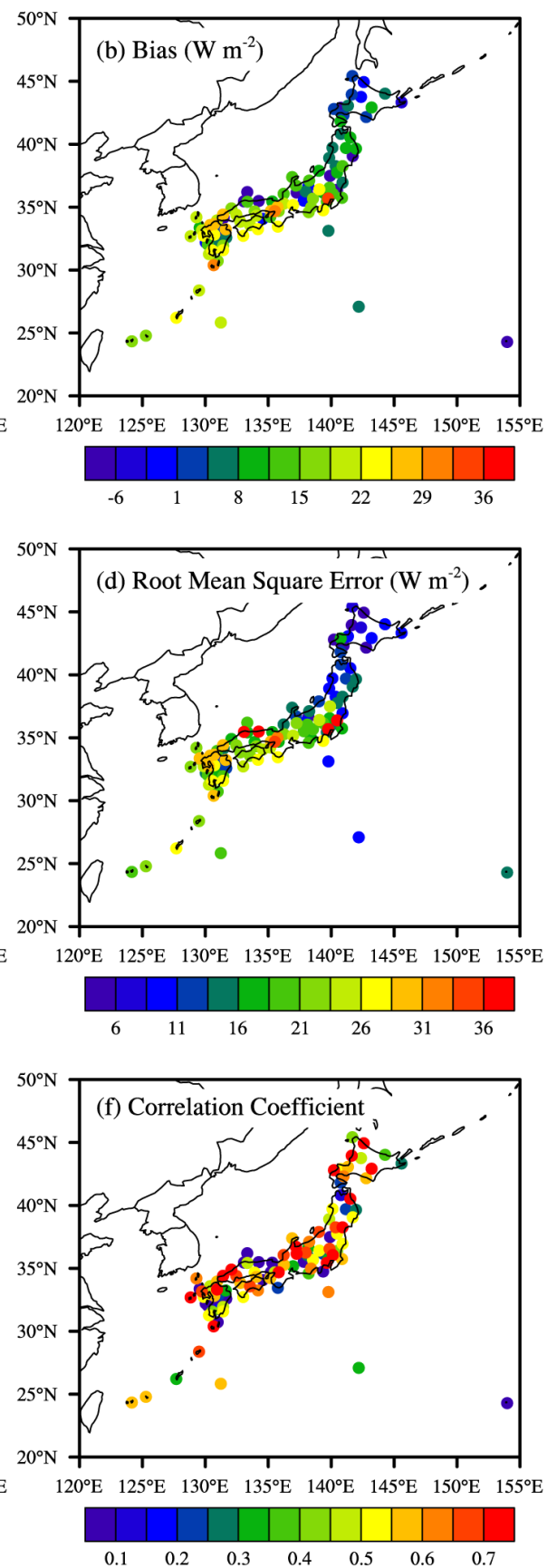

Figure 4. The spatial distribution of bias, root mean square error, and the correlation coefficient between SunDu-derived surface incident solar radiation $\left(R_{\mathrm{S}}\right)$ and observed $R_{\mathrm{S}}$ before $(\mathbf{a}, \mathbf{c}, \mathbf{e})$ and after $(\mathbf{b}, \mathbf{d}, \mathbf{f})$ homogenization. Improvements were made at most sites after homogenization.

\subsection{Uncertainties in $R_{\mathrm{S}}$ observations}

Figure 9 displays the change in $R_{\mathrm{S}}$ during the last 5 decades, while Fig. 10 shows the variation in observed clouds over Japan. The sharp decrease in $R_{\mathrm{S}}$ in 1963 caused by the volcanic eruption of Mount Agung in Indonesia (Witham, 2005) can be clearly found. The sharp decreases in $R_{\mathrm{S}}$ in 1991 and 1993 are due to the combined effect of the volcanic eruption of Mount Pinatubo in the Philippines in 1991 (Robock, 2000) and the simultaneous significant increases in clouds (Fig. 8 in Tsutsumi and Murakami, 2012). The volcanic eruption of El Chichón in Mexico in 1982 exerted little impact on the de- 
Table 1. Trends of surface incident solar radiation $\left(R_{\mathrm{S}}\right)$ in Japan during specific time periods for different types of datasets ${ }^{\mathrm{a}}$. Unit: $\mathrm{W} \mathrm{m}{ }^{-2}$ per decade.

\begin{tabular}{llllll}
\hline Case $^{\text {b }}$ & Datasets $^{c}$ & $1961-1980$ & $1981-1995$ & $1996-2014$ & $1961-2014$ \\
\hline Selected 41 stations & OBS-raw & $-12.0^{* *}$ & -2.1 & 2.4 & -0.3 \\
& OBS_HM & $-4.8^{*}$ & -2.1 & 2.4 & $1.5^{* *}$ \\
\cline { 2 - 6 } & OBS_2HM & $-0.8^{*}$ & -2.1 & $2.4^{*}$ & $0.9^{* *}$ \\
\cline { 2 - 6 } & SunDu-derived & 1.4 & $-11.3^{* *}$ & 1.4 & $-2.1^{* *}$ \\
\cline { 2 - 6 } & SunDu-derived_HM & 1.4 & $-1.3^{*}$ & 1.5 & $0.9^{* *}$ \\
\hline \multirow{2}{*}{ All stations } & OBS-raw & $-11.2^{* *}$ & -1.3 & 2.2 & 0.2 \\
\cline { 2 - 6 } & OBS_HM & $-8.4^{* *}$ & -1.3 & 2.2 & 0.8 \\
\cline { 2 - 6 } & OBS_2HM & 0.7 & -1.3 & 2.2 & $1.6^{* *}$ \\
\cline { 2 - 6 } & SunDu-derived & $2.3^{*}$ & $-10.6^{* *}$ & 1.2 & $-1.9^{* *}$ \\
\cline { 2 - 6 } & SunDu-derived_HM & 1.6 & -1.2 & 1.4 & $0.9^{*}$ \\
\hline Radiative effect & CCRE series & -1.1 & -1.4 & -0.0 & $-1.4^{* *}$ \\
& Residual series & $2.4^{* *}$ & -0.1 & $1.2^{*}$ & $2.2^{* *}$ \\
\hline
\end{tabular}

a The trend calculations were based on the linear regression method. Values with two asterisks $\left.{ }^{* *}\right)$ imply $p<0.01$, and those with one asterisk $\left(^{*}\right)$ imply $0.01<p<0.1$.

${ }^{\mathrm{b}} R_{\mathrm{S}}$ trends were calculated by different numbers of observations, including all stations that are available on the JMA website and 41 stations (marked with red in Table S1, detailed in Sect. 3.1) that are significantly improved after homogenization. This implies that the sample number has a subtle impact on the trend calculation over Japan. Radiative effects from clouds and aerosols were also explored.

c Trend calculations were based on the raw (observational) measurements of surface incident solar radiation (OBS-raw), their homogenized series (OBS_HM), derived incident solar radiation from sunshine duration hours (SunDu-derived), and their homogenized series (SunDu-derived_HM). OBS_HM from 1961 to 1970 was further homogenized by using SunDu-derived_HM as reference data, termed OBS 2HM. It is found that homogenized SunDu-derived $R_{\mathrm{S}}$ values have the lowest uncertainties among these five datasets in Sect. 3.1. The cloud cover radiative effect (CCRE) was denoted as the change in $R_{\mathrm{S}}$ produced by a change in cloud cover, and the CCRE calculations were performed following Eq. (4) by observed cloud amounts and the cloud radiative effect (CRE) from CERES satellite retrieval. Residual effect series were obtained by removing the CCRE from homogenized SunDu-derived $R_{\mathrm{S}}$ anomalies.

cline in $R_{\mathrm{s}}$ and may have been compensated by the decrease in clouds, as shown in Fig. 10. The pronounced $R_{\mathrm{S}}$ decline in 1980 coincides with the significant increase in clouds, while the lightening of $R_{\mathrm{S}}$ in 1978 and 1994 encounters abrupt decreases in cloud covers.

As shown in Fig. 9, no major modifications were found in $R_{\mathrm{S}}$ observations before and after homogenization (comparison between the light-blue and dark-blue lines). However, the SunDu-derived $R_{\mathrm{s}}$ series are smoother after adjustment by the QM method, as the sharp decrease from 1983 to 1993 caused by the replacement of sunshine duration instruments (Jordan recorders were replaced with EKO rotating-mirror recorders) (Stanhill and Cohen, 2008) was repaired (comparison between the light-red line and dark-red lines). Despite the identical increase in $R_{\mathrm{S}}$ via both the homogenized direct measurements of $R_{\mathrm{S}}$ and the homogenized SunDu-derived $R_{\mathrm{S}}$ during the 1995-2014 period, their variations in $R_{\mathrm{S}}$ from 1961 to 1994 are different (dark-red line and dark-blue line).

Large discrepancies in $R_{\mathrm{S}}$ variation were found during the time period of 1961-1970, although homogenization was performed on the direct measurements of $R_{\mathrm{S}}$ and SunDuderived $R_{\mathrm{S}}$ (dark-blue line and dark-red line in Fig. 9). An existing study noted the inaccurate instruments used at the beginning of operation in the $R_{\mathrm{s}}$ observation network in approximately 1961, and the parallel use of two different types of instruments during the 1960s may result in the large variability in observed $R_{\mathrm{S}}$ (Tanaka et al., 2016). At this time, the clouds fluctuated gently, as shown in Fig. 10, and the change in volcanic aerosols from 1965 to 1966 was nearly the same as that from 1962 to 1963 (Table 2 in Sato et al., 1993), so the sudden decline in the direct observations of $R_{\mathrm{S}}$ from 1965 to 1966 , which was twice as large as that from 1962 to 1963 , is suspicious. It is inferred that anthropogenic aerosols play a subtle role in the significant reduction in $R_{\mathrm{S}}$, as this type of phenomenon is common for both polluted and pristine stations in Japan (Fig. 22 in Tanaka et al., 2016).

Figure 11 shows the correlation coefficients between homogenized $R_{\mathrm{S}}$ (observed and SunDu-derived) and cloud amount. In general, the observed $R_{\mathrm{S}}(-0.45)$ is less correlated than the SunDu-derived $R_{\mathrm{S}}(-0.67)$, particularly from 1961 to $1970,-0.21$ compared with -0.64 . This in turn supports the reliability of homogenized SunDu-derived $R_{\mathrm{S}}$, especially during the time period of 1961-1970. The false variability of the observed $R_{\mathrm{s}}$ from 1961 to 1970 was modified by the RHtests method against the homogenized SunDu-derived $R_{\mathrm{S}}$ as shown in Fig. 12. 

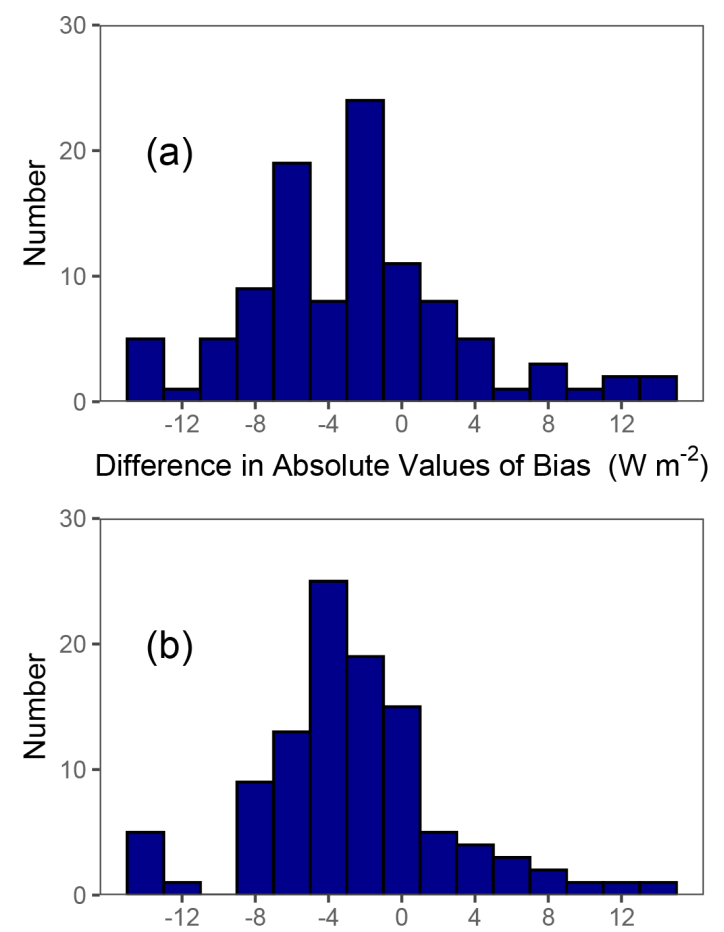

Difference in Root Mean Square Error $\left(\mathrm{W} \mathrm{m}^{-2}\right)$

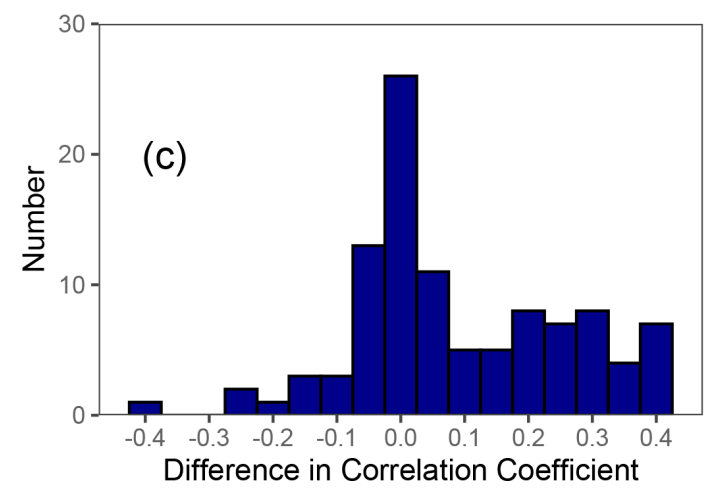

Figure 5. Histograms of the difference of (a) absolute values of bias, (b) root mean square error, and (c) correlation coefficient between SunDu-derived surface incident solar radiation $\left(R_{\mathrm{S}}\right)$ and observed $R_{\mathrm{S}}$ before and after homogenization. Their differences decrease after homogenization.

General decreases in stratospheric aerosol optical depth (AOD) were reported in Sato et al. (1993) from 1965 to 1980, and clouds fluctuated slightly, as shown in Fig. 10; both of these factors contributed to a brightening of $R_{\mathrm{s}}$. This is in agreement with the SunDu-derived $R_{\mathrm{S}}$ and contrasts with the direct measurements of $R_{\mathrm{S}}$.

During the 1985-1990 period, clouds varied slightly, as shown in Fig. 10, and the observed atmospheric transmission under cloud-free conditions increased (Wild et al., 2005), which suggests that the large declines in directly observed $R_{\mathrm{S}}$ and SunDu-derived $R_{\mathrm{S}}$ are defective and reinforce the re-

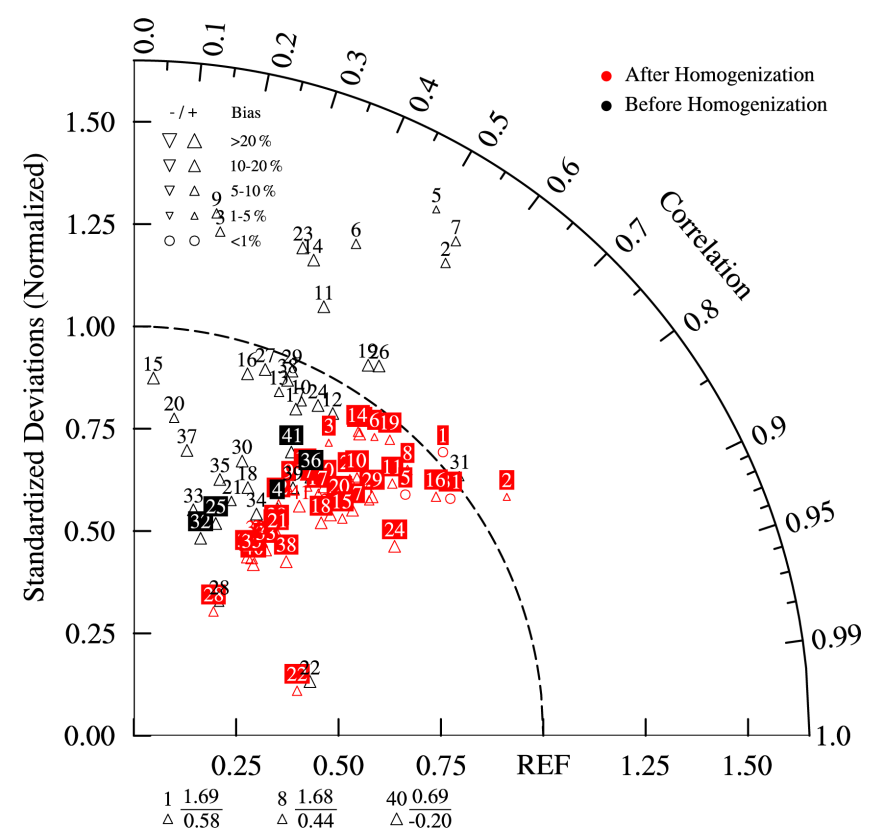

Figure 6. Taylor diagram describing the relative biases, standardized deviations, and correlation coefficients between the annual observed surface incident short-wave radiation $\left(R_{\mathrm{S}}\right)$ and annual sunshine-duration-derived (SunDu-derived) $R_{\mathrm{S}}$ before and after homogenization at 41 selected stations (numbered 1-41 here). "REF" can be treated as the perfect point, where values the closer to this point indicate a better evaluation. The size and direction of the triangles denote the magnitude and negativity or positivity of biases, respectively. The boxes indicate the smaller bias in raw (black colour) or HM (red colour) series. This figure shows that biases decrease at most sites (in red boxes) after homogenization, except for the five stations numbered 4, 25, 32, 36, and 41 (in black boxes). Three stations (numbered 1, 8, and 40 in black colour) listed below the panel are beyond the scope of the figure, with the bias (triangle), ratio of the standardized deviation (above the - line), and correlation coefficient (below the - line) shown. In addition to the improvements in the correlation coefficients after homogenization, the biases and the standard deviations generally become small in this Taylor diagram.

liability of the adjusted SunDu-derived $R_{\mathrm{S}}$ (dark-red line in Fig. 9).

From the above analysis, it can be inferred that fewer uncertainties exist in homogenized SunDu-derived $R_{\mathrm{S}}$, which was confirmed by another work that utilized a different dataadjusted method (Stanhill and Cohen, 2008).

\subsection{Trends of $R_{\mathrm{S}}$ over Japan}

The trends of $R_{\mathrm{S}}$ during specific time periods for different types of datasets are listed in Table 1. Direct measurements of $R_{\mathrm{S}}$ and SunDu-derived $R_{\mathrm{S}}$ from 41 selected stations and all available stations reveal similar variations in $R_{\mathrm{S}}$ over Japan, which demonstrates that the sample number has a subtle impact on the estimation of global brightening and dimming over Japan. 


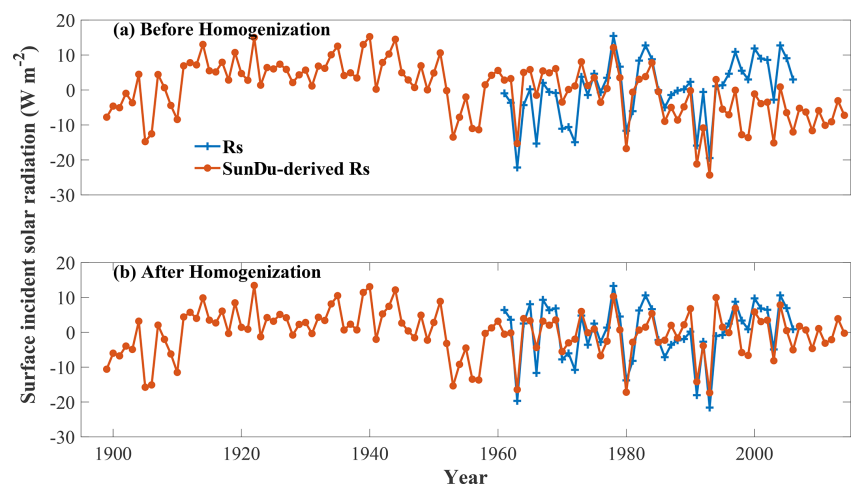

Figure 7. Time series of annual anomalies of observed surface incident solar radiation $\left(R_{\mathrm{S}}\right)$ and SunDu-derived $R_{\mathrm{S}}$ at the Hamada site (WMO ID: 47755; lat 34.9, long 132.07) before and after homogenization.

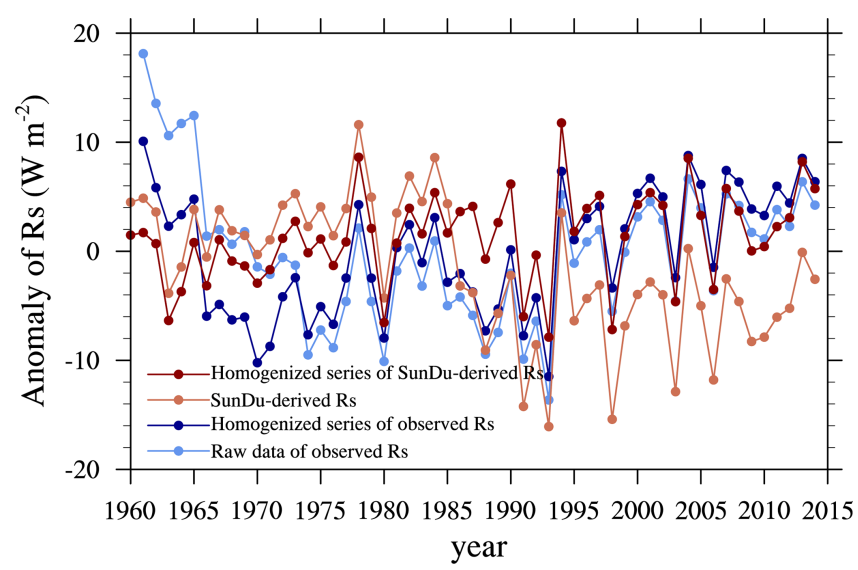

Figure 8. Time series of annual anomalies of surface incident solar radiation $\left(R_{\mathrm{S}}\right)$ based on direct $R_{\mathrm{S}}$ observations (light-blue line) and their homogenized series (dark-blue line) and sunshine-durationderived (SunDu-derived) $R_{\mathrm{S}}$ (light-red line) and their homogenized series (dark-red line). All of the lines were calculated based on observations at 41 sites. Details on how these 41 sites were selected are given in Sect. 3.1. The $R_{\mathrm{S}}$ variations are nearly the same as those shown in Fig. 7, which were calculated based on all available observations.

A revisit of global dimming and brightening was listed in Table 1. Major differences were found in the time period of 1961-1980, ranging from $-11.2(-12.0)$ to $-8.4(-4.8) \mathrm{W} \mathrm{m}^{-2}$ per decade before and after $R_{\mathrm{S}}$ homogenization for all available stations (41 selected stations) over Japan; significant repairs occurred during the 1981-1995 period, ranging from $-10.6(-11.3)$ to -1.2 $(-1.3) \mathrm{W} \mathrm{m}^{-2}$ per decade before and after SunDu-derived $R_{\mathrm{S}}$ homogenization for all available stations (41 selected stations) over Japan. Both corrections were mainly attributed to the homogenization of corrupted raw data caused by the replacement of instruments for $R_{\mathrm{S}}$ and SunDu measurements. After careful checking and adjustment of the SunDu-derived

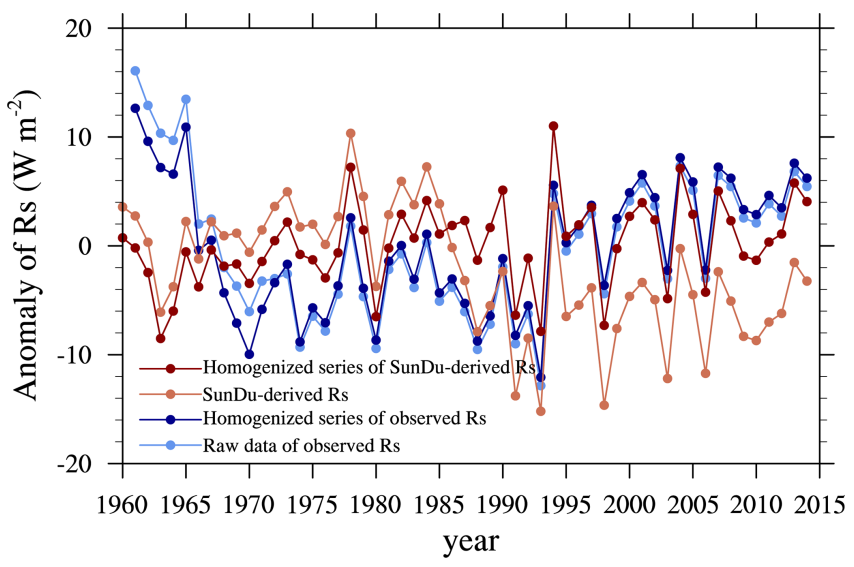

Figure 9. Time series of annual anomalies of the surface incident solar radiation $\left(R_{\mathrm{S}}\right)$ based on direct observations (light-blue line) and their homogenized series (dark-blue line) and sunshineduration-derived (SunDu-derived) $R_{\mathrm{S}}$ (light-red line) and their homogenized series (dark-red line). All of the lines were calculated based on as many observations as possible. The light-blue line and dark-blue line were calculated from the $R_{\mathrm{S}}$ observations at 105 sites, while the light-red line and dark-red line were derived from the SunDu-derived $R_{\mathrm{S}}$ at 156 sites. The $R_{\mathrm{S}}$ variations are nearly the same as those shown in Fig. 6, which were calculated based on the 41 selected sites in Sect. 3.1. Large discrepancies were found in the homogenized data series (dark-blue and dark-red lines).

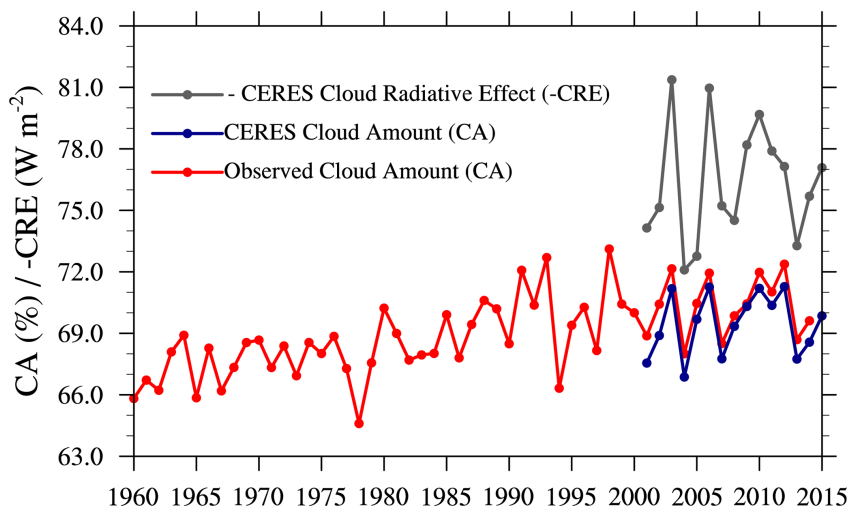

Figure 10. The cloud amount (CA) from CERES (blue line) agrees well with that derived from surface observations (red line) over Japan. At the annual timescale, the negative cloud radiative effect (-CRE, grey line) in CERES correlated well with the cloud amount.

$R_{\mathrm{S}}$ series, the decadal variation in $R_{\mathrm{S}}$ over Japan, which was totally different from former studies (Wild et al., 2005; Norris and Wild, 2009), was remedied. Direct measurements of $R_{\mathrm{S}}$ display a trend of nearly zero from 1961 to 2014 over Japan, while their homogenization series report a positive change of $0.8-1.6 \mathrm{~W} \mathrm{~m}^{-2}$ per decade; SunDu-derived $R_{\mathrm{S}}$ decreases at a rate of $1.9 \mathrm{~W} \mathrm{~m}^{-2}$ per decade, while its homogenized series reveals a brightening of $0.9 \mathrm{~W} \mathrm{~m}^{-2}$ per decade.

The combined effects of clouds and aerosols on $R_{\mathrm{S}}$ make the global dimming and brightening complicated. 


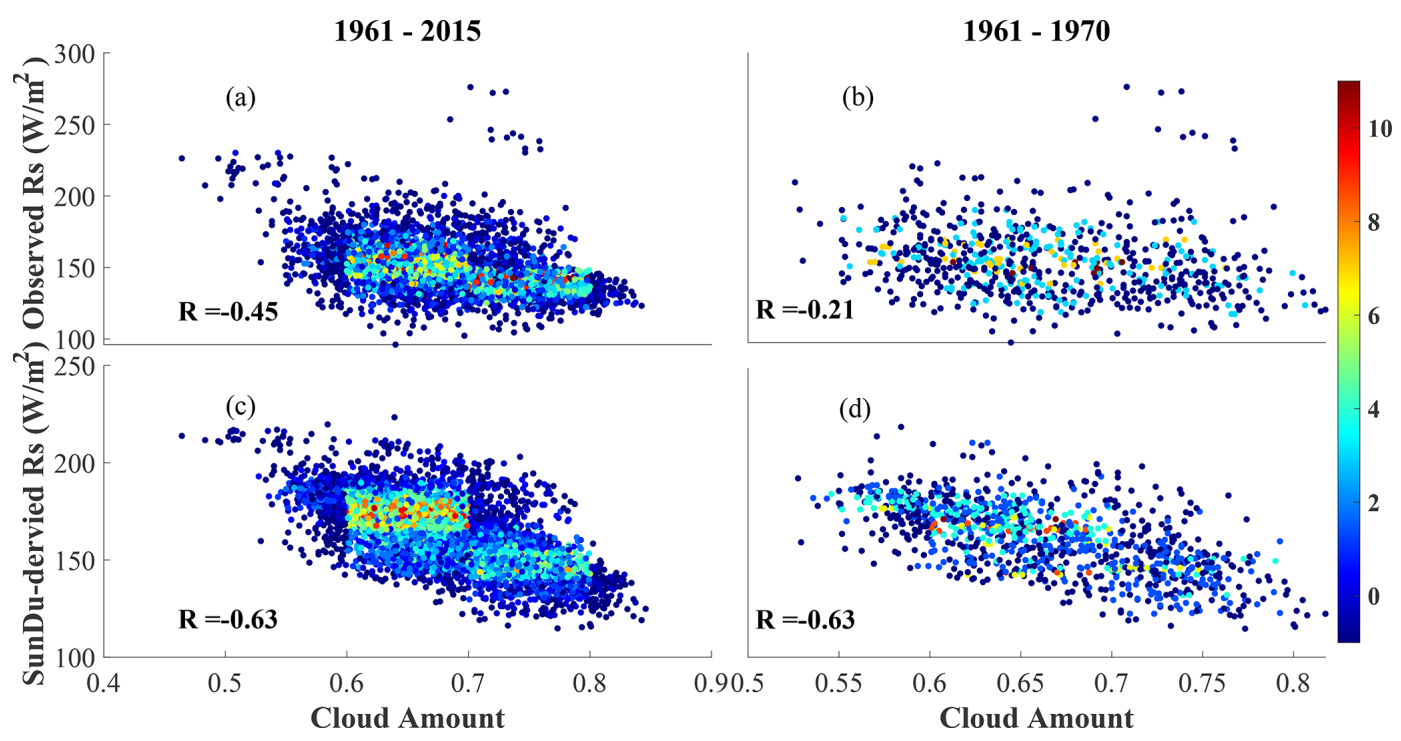

Figure 11. Scatter plot of homogenized monthly surface incident solar radiation $\left(R_{\mathrm{S}}\right)$ (observed and SunDu-derived solar radiation) as a function of ground-based observations of cloud amount over Japan at all stations only when both cloud amount data and observed $R_{\mathrm{S}}$ data are available: (a, c) for 1961-2015 and (b, d) for 1961-1970. The smallest correlation coefficient in (b) indicates that the observed $R_{\mathrm{S}}$ data are spurious for 1961-1970 and that SunDu-derived $R_{\mathrm{S}}$ are more convincing.

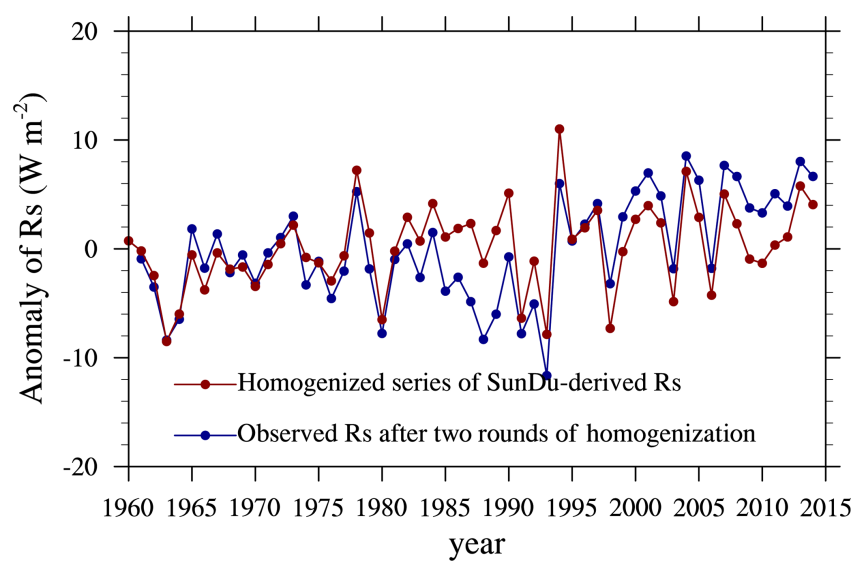

Figure 12. Time series of annual anomalies of the surface incident solar radiation $\left(R_{\mathrm{S}}\right)$ based on $R_{\mathrm{S}}$ observations after two rounds of homogenization (dark-blue line). The homogenized series of observed $R_{\mathrm{S}}$ from 1961 to 1970 shown in Fig. 7 was tuned by the RHtests method again using the homogenized series of SunDuderived $R_{\mathrm{S}}$ (dark-red line in Figs. 7 and 10) as a reference.

The CCRE can explain $70 \%$ of global brightening from 1961 to 2014 at monthly and interannual timescales, while the residual radiative effect dominates the decadal variation in $R_{\mathrm{S}}$, as shown in Fig. 13 and Table 1, which is in agreement with Wang et al. (2012). Homogenized SunDuderived $R_{\mathrm{S}}$ shows an increase of $1.6 \mathrm{~W} \mathrm{~m}^{-2}$ per decade from 1961 to 1980; however, a persistent increase in cloud amount yields a CCRE decrease of $1.1 \mathrm{~W} \mathrm{~m}^{-2}$ per decade. The residual radiative effect accounts for an increase of

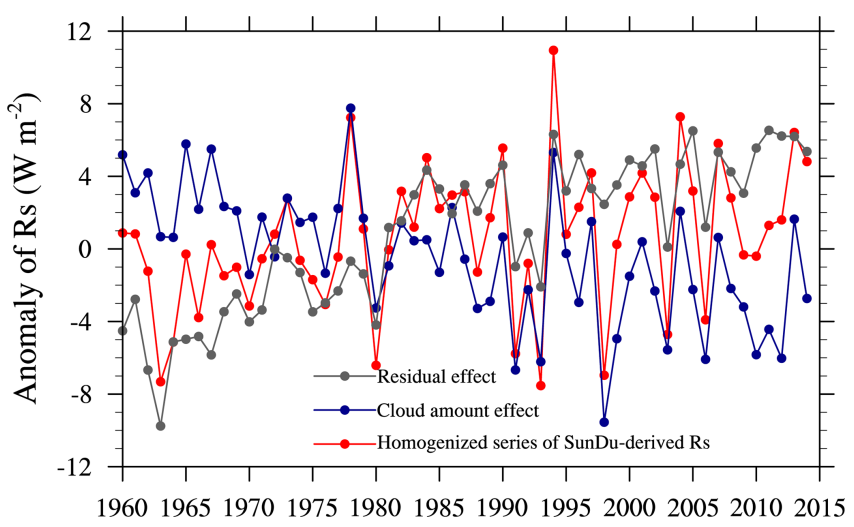

Figure 13. Area-averaged anomalies of homogenized SunDuderived $R_{\mathrm{S}}$ (red line) over Japan. The cloud cover radiative effect (CCRE, blue line) was denoted as the change in $R_{\mathrm{S}}$ produced by a change in cloud cover and calculated following Eq. (4) by observed cloud amounts and the cloud radiative effect (CRE) from the CERES satellite retrieval. The residual effect (grey line) was obtained by removing the cloud cover radiative effect (CCRE) from the homogenized SunDu-derived $R_{\mathrm{S}}$ anomalies.

$2.4 \mathrm{~W} \mathrm{~m}^{-2}$ per decade for this time period. The cloud radiative effect $\left(-1.4 \mathrm{~W} \mathrm{~m}^{-2}\right.$ per decade) modulates $R_{\mathrm{S}}$ variation of $-1.2 \mathrm{~W} \mathrm{~m}^{-2}$ per decade for the 1981-1995 period, while the residual radiative effect $\left(1.2 \mathrm{~W} \mathrm{~m}^{-2}\right.$ per decade) dominates $R_{\mathrm{S}}$ variation of $1.4 \mathrm{~W} \mathrm{~m}^{-2}$ per decade from 1996 to 2014.

Homogenized SunDu-derived $R_{\mathrm{S}}$ shows a slight increase of $0.9 \mathrm{~W} \mathrm{~m}^{-2}$ per decade from 1961 to 2014 with a $90 \%$ confidence interval. However, the CCRE accounts for a deceased 
$R_{\mathrm{S}}$ of $1.4 \mathrm{~W} \mathrm{~m}^{-2}$ per decade, which implies that cloud cover changes are not the primary driving forces for the $R_{\mathrm{S}}$ trend over Japan. Meanwhile, the residual radiative effect exhibits an increase of $2.2 \mathrm{~W} \mathrm{~m}^{-2}$ per decade, which surpasses the negative CCRE.

Several studies demonstrate a generally cleaner sky over Japan from the 1960s to the 2000s (except for the years impacted by volcanic eruptions) based on atmospheric transparency and aerosol optical properties (Wild et al., 2005; Kudo et al., 2012), which supports the dominant role of aerosols in $R_{\mathrm{s}}$ brightening over Japan, as revealed by the residual radiative effect here. Furthermore, the residual radiative effect in this study is stronger than that in Norris and Wild (2009), as raw data were remedied and more accurate satellite data from CERES were adopted to quantify the radiative effect. Tsutsumi and Murakami (2012) demonstrate that cloud amount categories exert an important effect on $R_{\mathrm{S}}$ variation. $R_{\mathrm{S}}$ enhancement by the increased appearance of large cloud amounts is superior to $R_{\mathrm{S}}$ decline by the decreased appearance of small cloud amounts during 19612014 , which yields increased $R_{\mathrm{S}}$ with increasing total cloud amount. They also pointed out that the decrease in cloud optical thickness due to the large emissions of $\mathrm{SO}_{2}$ and black carbon from East Asia through the aerosol semi-direct effect (absorption of more energy by aerosols results in the evaporation or suppression of clouds) may have facilitated the increased $R_{\mathrm{S}}$ over Japan.

The decrease in spring dust storms in March-May during the last 5 decades from China (Qian et al., 2002; Zhu et al., 2008), which may travel to neighbouring countries (Uno et al., 2008; Choi et al., 2001), could also have triggered the increase in $R_{\mathrm{S}}$ over Japan. The $R_{\mathrm{S}}$ variation and radiative effect in different seasons are categorized in Fig. 14 and Table 2 , in which an increasing trend of $1.5 \mathrm{~W} \mathrm{~m}^{-2}$ per decade in the homogenized SunDu-derived $R_{\mathrm{S}}$ prevails in spring for the whole time period, dominated by a dramatic increase of $2.8 \mathrm{~W} \mathrm{~m}^{-2}$ per decade in the residual effect and an even larger increase for $1961-1980\left(3.1 \mathrm{~W} \mathrm{~m}^{-2}\right.$ per decade $)$ and 1996-2014 (3.4 $\mathrm{W} \mathrm{m}^{-2}$ per decade).

\section{Data availability}

Monthly observed surface incident solar radiation, sunshine duration, and cloud amount data were provided by Japan Meteorological Agency (2022; https://www.data.jma. go.jp/obd/stats/data/en/smp/index.html, last access: 21 January 2022), and monthly cloud radiative effect (CRE) data were derived from Clouds and the Earth's Radiant Energy System for CERES EBAF data (https://ceres. larc.nasa.gov/order_data.php, last access: 21 January 2022; CERES Science Team, 2022). The homogenized observed $R_{\mathrm{S}}$ and SunDu-derived $R_{\mathrm{S}}$ used in this study are available at https://doi.org/10.11888/Meteoro.tpdc.271524 (Ma et al., 2021).
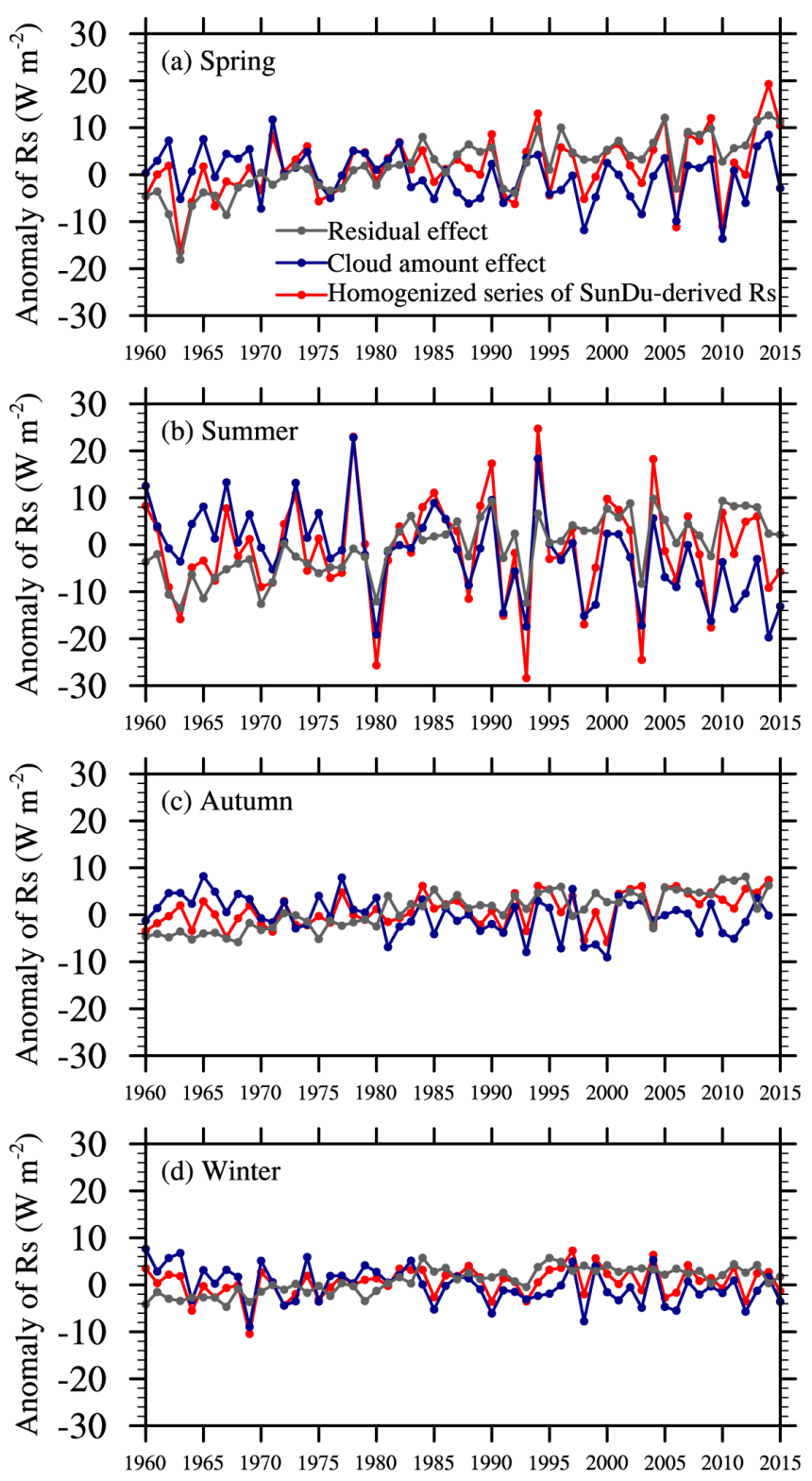

Figure 14. Same as Fig. 12 but for the four seasons. The decrease in Asian spring dust may have triggered the brightening over Japan for 1961-2015, as the $R_{\mathrm{S}}$ in spring increases most among the seasons.

\section{Conclusions}

The homogenization of raw observations related to $R_{\mathrm{S}}$ can significantly improve the accuracy of global dimming and brightening estimation and provide a reliable assessment of climate trends and variability. In this study, we for the first time homogenized the raw $R_{\mathrm{S}}$ observations and obtained a more reliable $R_{\mathrm{S}}$ data series over Japan for a century.

Documented artificial shifts in metadata play an important role in regulating the raw observations. If change points were confirmed by metadata or other independent climate variables, the RHtests method was applied to remove the dis- 
Table 2. Trends of surface incident solar radiation $\left(R_{\mathrm{S}}\right)$ in Japan during specific time periods for different types of datasets for all seasons. Unit: $\mathrm{W} \mathrm{m}^{-2}$ per decade.

\begin{tabular}{|c|c|c|c|c|c|}
\hline Season & Datasets & $1961-1980$ & 1981-1995 & 1996-2014 & 1961-2014 \\
\hline \multirow[t]{3}{*}{ Spring } & SunDu-derived_HM & 3.1 & -1.5 & $3.4^{*}$ & 1.5 \\
\hline & CCRE series & -0.7 & -1.6 & -1.6 & -0.9 \\
\hline & Residual series & $4.9^{* *}$ & $-0.5^{* *}$ & $2.2^{* *}$ & $2.8^{*}$ \\
\hline \multirow[t]{3}{*}{ Summer } & SunDu-derived_HM & 1.4 & -3.4 & 0.6 & 0.4 \\
\hline & CCRE series & -1.9 & -2.1 & $-4.4^{* *}$ & -2.7 \\
\hline & Residual series & $2.0^{* *}$ & -1.8 & $1.5^{* *}$ & 2.8 \\
\hline \multirow[t]{3}{*}{ Autumn } & SunDu-derived_HM & 0.6 & 1.5 & $3.3^{* *}$ & $1.0^{*}$ \\
\hline & CCRE series & $-1.3^{* *}$ & 1.6 & 1.6 & -0.9 \\
\hline & Residual series & $1.8^{* *}$ & $0.8^{* *}$ & $2.1^{* *}$ & $2.0^{*}$ \\
\hline \multirow[t]{3}{*}{ Winter } & SunDu-derived_HM & 0.6 & -1.5 & -1.6 & 0.5 \\
\hline & CCRE series & -0.6 & -3.3 & -0.6 & -0.7 \\
\hline & Residual series & $1.1^{* *}$ & $0.9^{* *}$ & $-0.9^{* *}$ & $1.2^{* *}$ \\
\hline
\end{tabular}

continuities. In this study, shifts in the homogenized raw $R_{\mathrm{S}}$ were further checked by exploring the relationship with the ground-based cloud amount and tuned again using homogenized SunDu-derived $R_{\mathrm{S}}$ as the reference data. By comparing the variations in independent climate variables of clouds and aerosols, the homogenized SunDu-derived $R_{\mathrm{S}}$ proved to be more reliable in detecting $R_{\mathrm{S}}$ variability over Japan.

A revisit of global dimming and brightening is made based on the homogenized $R_{\mathrm{S}}$ series. $R_{\mathrm{S}}$ over Japan increases at a rate of $1.6 \mathrm{~W} \mathrm{~m}^{-2}$ per decade for 1961-1980, which is contrary to the trend $\left(-4.8\right.$ to $-12.0 \mathrm{~W} \mathrm{~m}^{-2}$ per decade) in the unreasonable $R_{\mathrm{S}}$ observation. A slight decrease of $1.2 \mathrm{~W} \mathrm{~m}^{-2}$ per decade for 1981-1995 in homogenized SunDu-derived $R_{\mathrm{S}}$ accounts for only $1 / 10$ of the trend in its unadjusted series. This directly contributes a brightening of $0.9 \mathrm{~W} \mathrm{~m}^{-2}$ per decade (with a $99 \%$ confidence interval) for the last 5 decades in homogenized series, which is totally contrary to the variation in its original series. Global brightening since 1961 over Japan is consistent with that in Stanhill and Cohen (2008), except that the magnitude is not as large.

We also explored how the clouds and aerosols mediate the transformation of $R_{\mathrm{s}}$. The brightening in Japan for 19611980 was the combined effect of cloud cover (negative effect) and aerosols (positive effect). The dimming for 1981-1995 was governed by reduced cloud amounts, while the increase in $R_{\mathrm{S}}$ for 1996-2014 was controlled by decreased aerosols. These results are different from those in Norris and Wild (2009), as homogenization was performed on the raw data, and more accurate cloud radiative effect data series from CERES were utilized in our study. During the entire period of
1961-2014, cloud amounts dominated seasonal and interannual $R_{\mathrm{S}}$ variations, while aerosols (including aerosol-cloud interactions) drove decadal $R_{\mathrm{S}}$ variations over Japan, noted by other studies, in response to general cleaner skies and a reduction in spring Asian dust storms (Wang et al., 2012; Kudo et al., 2012).

Supplement. The supplement related to this article is available online at: https://doi.org/10.5194/essd-14-463-2022-supplement.

Author contributions. QM and KW designed the research and wrote the paper. LS collected the raw data. YH homogenized the raw data. QW provided the technical support. YZ and HL checked the data.

Competing interests. The contact author has declared that neither they nor their co-authors have any competing interests.

Disclaimer. Publisher's note: Copernicus Publications remains neutral with regard to jurisdictional claims in published maps and institutional affiliations.

Acknowledgements. This study is funded by the National Key R\&D Program of China (grant no. 2017YFA0603601) and the National Science Foundation of China (grant no. 41930970), and the project is supported by the State Key Laboratory of Earth Surface Processes and Resource Ecology (grant no. 2017-KF-03). We thank 
many institutions for sharing their data, including the Japan Meteorological Agency for observation data over Japan (https://www.data. jma.go.jp/obd/stats/data/en/smp/index.html, last access: 21 January 2022) and Clouds and the Earth's Radiant Energy System for CERES EBAF data (https://ceres.larc.nasa.gov/order_data.php, last access: 21 January 2022). We thank the Expert Team on Climate Change Detection and Indices (ETCCDI) for providing the RHtestsV4 homogenization package (http://etccdi.pacificclimate.org/ software.shtml, last access: 21 January 2022).

Financial support. This research has been supported by the National Key R\&D Program of China (grant no. 2017YFA0603601) and the National Science Foundation of China (grant no. 41930970), and the project is supported by the State Key Laboratory of Earth Surface Processes and Resource Ecology (grant no. 2017-KF-03).

Review statement. This paper was edited by Bo Zheng and reviewed by two anonymous referees.

\section{References}

Aguilar, E., Auer, I., Brunet, M., Peterson, T. C., and Wieringa, J.: Guidelines on climate metadata and homogenization, World Meteorological Organization, Geneva, WMO-TD No. 1186, 55 pp., 2003.

Alexandersson, H.: A homogeneity test applied to precipitation data, J. Climatol., 6, 661-675, https://doi.org/10.1002/joc.3370060607, 1986.

Allen, R. J., Norris, J. R., and Wild, M.: Evaluation of multidecadal variability in CMIP5 surface solar radiation and inferred underestimation of aerosol direct effects over Europe, China, Japan, and India, J. Geophys. Res.-Atmos., 118, 6311-6336, https://doi.org/10.1002/jgrd.50426, 2013.

Augustine, J. A. and Hodges, G. B.: Variability of Surface Radiation Budget Components Over the U.S. From 1996 to 2019-Has Brightening Ceased?, J. Geophys. Res.-Atmos., 126, e2020JD033590, https://doi.org/10.1029/2020JD033590, 2021.

CERES Science Team: Dataset of CERES EBAF, NASA LaRC [data set], https://ceres.larc.nasa.gov/data/, last access: 21 January 2022.

Choi, J. C., Lee, M., Chun, Y., Kim, J., and Oh, S.: Chemical composition and source signature of spring aerosol in Seoul, Korea, J. Geophys. Res., 106, 18067-18074, https://doi.org/10.1029/2001JD900090, 2001.

Dai, A., Wang, J., Thorne, P. W., Parker, D. E., Haimberger, L., and Wang, X. L.: A New Approach to Homogenize Daily Radiosonde Humidity Data, J. Climate, 24, 965-991, https://doi.org/10.1175/2010JCLI3816.1, 2011.

Du, J., Wang, K., Cui, B., and Jiang, S.: Correction of Inhomogeneities in Observed Land Surface Temperatures over China, J. Climate, 33, 8885-8902, https://doi.org/10.1175/JCLI-D-190521.1, 2020.

Dwyer, J. G., Norris, J. R., and Ruckstuhl, C.: Do climate models reproduce observed solar dimming and brightening over China and Japan?, J. Geophys. Res., 115, D00K08, https://doi.org/10.1029/2009JD012945, 2010.

Feng, F. and Wang, K.: Merging ground-based sunshine duration observations with satellite cloud and aerosol retrievals to produce high-resolution long-term surface solar radiation over China, Earth Syst. Sci. Data, 13, 907-922, https://doi.org/10.5194/essd13-907-2021, 2021a.

Feng, F. and Wang, K.: Merging High-Resolution Satellite Surface Radiation Data with Meteorological Sunshine Duration Observations over China from 1983 to 2017, Remote Sens., 13, 602, https://doi.org/10.3390/rs13040602, 2021b.

He, Y., Wang, K., Zhou, C., and Wild, M.: A Revisit of Global Dimming and Brightening Based on the Sunshine Duration, Geophys. Res. Lett., 45, 4281-4289, https://doi.org/10.1029/2018GL077424, 2018.

Inoue, T. and Matsumoto, J.: Seasonal and secular variations of sunshine duration and natural seasons in Japan, Int. J. Climatol., 23, 1219-1234, https://doi.org/10.1002/joc.933, 2003.

Japan Meteorological Agency (JMA): Tables of Monthly Climate Statistics, JMA [data set], https://www.data.jma.go.jp/obd/stats/ data/en/smp/index.html, last access: 21 January 2022.

Kato, S., Loeb, N. G., Rose, F. G., Doelling, D. R., Rutan, D. A., Caldwell, T. E., Yu, L., and Weller, R. A.: Surface Irradiances Consistent with CERES-Derived Top-of-Atmosphere Shortwave and Longwave Irradiances, J Climate, 26, 2719-2740, https://doi.org/10.1175/JCLI-D-12-00436.1, 2012.

Katsuyama, M.: On comparison between rotating mirror sunshine recorders and Jordan sunshine recorders, Weather Service Bulletin, 54, 169-183, 1987.

Kudo, R., Uchiyama, A., Ijima, O., Ohkawara, N., and Ohta, S.: Aerosol impact on the brightening in Japan, J. Geophys. Res., 117, D07208, https://doi.org/10.1029/2011JD017158, 2012.

Ma, Q., Wang, K. C., and Wild, M.: Impact of geolocations of validation data on the evaluation of surface incident shortwave radiation from Earth System Models, J. Geophys. Res.-Atmos., 120, 6825-6844, https://doi.org/10.1002/2014JD022572, 2015.

Ma, Q., He, Y., Wang, K., and Su, L.: Homogenized solar radiation data set over Japan (1870-2015), National Tibetan Plateau Data Center [dataset], 10.11888/Meteoro.tpdc.271524, 2021.

Manara, V., Beltrano, M. C., Brunetti, M., Maugeri, M., SanchezLorenzo, A., Simolo, C., and Sorrenti, S.: Sunshine duration variability and trends in Italy from homogenized instrumental time series (1936-2013), J. Geophys. Res.-Atmos., 120, 3622-3641, https://doi.org/10.1002/2014JD022560, 2015.

Manara, V., Brunetti, M., Celozzi, A., Maugeri, M., SanchezLorenzo, A., and Wild, M.: Detection of dimming/brightening in Italy from homogenized all-sky and clear-sky surface solar radiation records and underlying causes (1959-2013), Atmos. Chem Phys., 16, 11145-11161, https://doi.org/10.5194/acp-16-111452016, 2016.

Manara, V., Brunetti, M., Maugeri, M., Sanchez-Lorenzo, A., and Wild, M.: Sunshine duration and global radiation trends in Italy (1959-2013): To what extent do they agree?, J. Geophys. Res.-Atmos., 122, 4312-4331, https://doi.org/10.1002/2016JD026374, 2017.

Noguchi, Y.: Solar radiation and sunshine duration in East Asia, Arch. Meteor. Geophy. B, 29, 111-128, https://doi.org/10.1007/BF02278195, 1981. 
Norris, J. R. and Wild, M.: Trends in aerosol radiative effects over China and Japan inferred from observed cloud cover, solar "dimming", and solar "brightening", J. Geophys. Res., 114, D00D15, https://doi.org/10.1029/2008JD011378, 2009.

Ohmura, A.: Observed decadal variations in surface solar radiation and their causes, J. Geophys. Res., 114, D00D05, https://doi.org/10.1029/2008JD011290, 2009.

Qian, W., Quan, L., and Shi, S.: Variations of the Dust Storm in China and its Climatic Control, J. Climate, 15, 1216-1229, https://doi.org/10.1175/15200442(2002)015<1216:VOTDSI>2.0.CO;2, 2002.

Qian, Y., Kaiser, D. P., Leung, L. R., and Xu, M.: More frequent cloud-free sky and less surface solar radiation in China from 1955 to 2000, Geophys. Res. Lett., 33, L01812, https://doi.org/10.1029/2005g1024586, 2006.

Reeves, J., Chen, J., Wang, X. L., Lund, R., and Lu, Q. Q.: A Review and Comparison of Changepoint Detection Techniques for Climate Data, J. Appl. Meteorol. Clim., 46, 900-915, https://doi.org/10.1175/jam2493.1, 2007.

Robock, A.: Volcanic eruptions and climate, Rev. Geophys., 38, 191-219, https://doi.org/10.1029/1998RG000054, 2000.

Sanchez-Lorenzo, A. and Wild, M.: Decadal variations in estimated surface solar radiation over Switzerland since the late 19th century, Atmos. Chem. Phys., 12, 8635-8644, https://doi.org/10.5194/acp-12-8635-2012, 2012.

Sanchez-Lorenzo, A., Brunetti, M., Calbó, J., and MartinVide, J.: Recent spatial and temporal variability and trends of sunshine duration over the Iberian Peninsula from a homogenized data set, J. Geophys. Res., 112, D20115, https://doi.org/10.1029/2007JD008677, 2007.

Sanchez-Lorenzo, A., Calbó, J., and Martin-Vide, J.: Spatial and Temporal Trends in Sunshine Duration over Western Europe (1938-2004), J. Climate, 21, 6089-6098, https://doi.org/10.1175/2008jcli2442.1, 2008.

Sanchez-Lorenzo, A., Calbó, J., and Wild, M.: Global and diffuse solar radiation in Spain: Building a homogeneous dataset and assessing their trends, Global Planet. Change, 100, 343-352, https://doi.org/10.1016/j.gloplacha.2012.11.010, 2013.

Sanchez-Lorenzo, A., Wild, M., Brunetti, M., Guijarro, J. A., Hakuba, M. Z., Calbó, J., Mystakidis, S., and Bartok, B.: Reassessment and update of long-term trends in downward surface shortwave radiation over Europe (1939-2012), J. Geophys. Res.-Atmos., 120, 9555-9569, https://doi.org/10.1002/2015JD023321, 2015.

Sato, M., Hansen, J. E., McCormick, M. P., and Pollack, J. B.: Stratospheric aerosol optical depths, 1850-1990, J. Geophys. Res., 98, 22987-22994, https://doi.org/10.1029/93JD02553, 1993.

Shi, G. Y., Hayasaka, T., Ohmura, A., Chen, Z. H., Wang, B., Zhao, J. Q., Che, H. Z., and Xu, L.: Data quality assessment and the long-term trend of ground solar radiation in China, J. Appl. Meteorol. Clim., 47, 1006-1016, https://doi.org/10.1175/2007jamc1493.1, 2008.

Stanhill, G. and Cohen, S.: Solar Radiation Changes in the United States during the Twentieth Century: Evidence from Sunshine Duration Measurements, J. Climate, 18, 1503-1512, https://doi.org/10.1175/jcli3354.1, 2005.

Stanhill, G. and Cohen, S.: Solar Radiation Changes in Japan during the 20th Century: Evidence from Sunshine Duration
Measurements, J. Meteorol. Soc. Jpn., Ser. II, 86, 57-67, https://doi.org/10.2151/jmsj.86.57, 2008.

Tanaka, K., Ohmura, A., Folini, D., Wild, M., and Ohkawara, N.: Is global dimming and brightening in Japan limited to urban areas?, Atmos. Chem. Phys., 16, 13969-14001, https://doi.org/10.5194/acp-16-13969-2016, 2016.

Tang, W.-J., Yang, K., Qin, J., Cheng, C. C. K., and He, J.: Solar radiation trend across China in recent decades: a revisit with quality-controlled data, Atmos. Chem. Phys., 11, 393-406, https://doi.org/10.5194/acp-11-393-2011, 2011.

Tsutsumi, Y. and Murakami, S.: Increase in Global Solar Radiation with Total Cloud Amount from 33 Years Observations in Japan, J. Meteorol. Soc. Jpn., 90, 575-581, https://doi.org/10.2151/jmsj.2012-409, 2012.

Uno, I., Yumimoto, K., Shimizu, A., Hara, Y., Sugimoto, N., Wang, Z., Liu, Z., and Winker, D. M.: 3D structure of Asian dust transport revealed by CALIPSO lidar and a 4DVAR dust model, Geophys. Res. Lett., 35, L06803, https://doi.org/10.1029/2007GL032329, 2008.

Vincent, L. A., Wang, X. L., Milewska, E. J., Wan, H., Yang, F., and Swail, V.: A second generation of homogenized Canadian monthly surface air temperature for climate trend analysis, J. Geophys. Res., 117, D18110, https://doi.org/10.1029/2012JD017859, 2012.

Wang, K., Dickinson, R. E., Ma, Q., Augustine, J. A., and Wild, M.: Measurement Methods Affect the Observed Global Dimming and Brightening, J. Climate, 26, 4112-4120, https://doi.org/10.1175/JCLI-D-12-00482.1, 2013.

Wang, K., Ma, Q., Li, Z., and Wang, J.: Decadal variability of surface incident solar radiation over China: Observations, satellite retrievals, and reanalyses, J. Geophys. Res.-Atmos., 120, 65006514, https://doi.org/10.1002/2015JD023420, 2015.

Wang, K. C., Dickinson, R. E., Wild, M., and Liang, S.: Atmospheric impacts on climatic variability of surface incident solar radiation, Atmos. Chem. Phys., 12, 9581-9592, https://doi.org/10.5194/acp-12-9581-2012, 2012.

Wang, X. L.: Comments on "Detection of Undocumented Changepoints: A Revision of the Two-Phase Regression Model", J. Climate, 16, 3383-3385, https://doi.org/10.1175/15200442(2003)016<3383:Codouc >2.0.Co;2, 2003.

Wang, X. L.: Accounting for Autocorrelation in Detecting Mean Shifts in Climate Data Series Using the Penalized Maximal $t$ or $F$ Test, J. Appl. Meteorol. Clim., 47, 2423-2444, https://doi.org/10.1175/2008jamc1741.1, 2008a.

Wang, X. L.: Penalized maximal F test for detecting undocumented mean shift without trend change, J. Atmos. Ocean Tech., 25, 368-384, https://doi.org/10.1175/2007JTECHA982.1, 2008b.

Wang, X. L., Wen, Q. H., and Wu, Y.: Penalized Maximal $\mathrm{t}$ Test for Detecting Undocumented Mean Change in Climate Data Series, J. Appl. Meteorol. Clim., 46, 916-931, https://doi.org/10.1175/jam2504.1, 2007.

Wang, X. L., Chen, H. F., Wu, Y. H., Feng, Y., and Pu, Q. A.: New Techniques for the Detection and Adjustment of Shifts in Daily Precipitation Data Series, J. Appl. Meteorol. Clim., 49, 24162436, https://doi.org/10.1175/2010JAMC2376.1, 2010.

Wild, M. and Schmucki, E.: Assessment of global dimming and brightening in IPCC-AR4/CMIP3 models and ERA40, Clim. Dynam., 37, 1671-1688, https://doi.org/10.1007/s00382-0100939-3, 2011. 
Wild, M., Gilgen, H., Roesch, A., Ohmura, A., Long, C. N., Dutton, E. G., Forgan, B., Kallis, A., Russak, V., and Tsvetkov, A.: From Dimming to Brightening: Decadal Changes in Solar Radiation at Earth's Surface, Science, 308, 847-850, https://doi.org/10.1126/science.1103215, 2005.

Wild, M., Wacker, S., Yang, S., and Sanchez-Lorenzo, A.: Evidence for Clear-Sky Dimming and Brightening in Central Europe, Geophys. Res. Lett., 48, e2020GL092216, https://doi.org/10.1029/2020GL092216, 2021.

Witham, C. S.: Volcanic disasters and incidents: A new database, J. Volcanol. Geoth. Res., 148, 191-233, https://doi.org/10.1016/j.jvolgeores.2005.04.017, 2005.

Xia, X.: A closer looking at dimming and brightening in China during 1961-2005, Ann. Geophys., 28, 1121-1132, https://doi.org/10.5194/angeo-28-1121-2010, 2010.

Yang, K., Koike, T., and Ye, B. S.: Improving estimation of hourly, daily, and monthly solar radiation by importing global data sets, Agr. Forest Meteorol., 137, 43-55, https://doi.org/10.1016/j.agrformet.2006.02.001, 2006.
Yang, S., Wang, X. L., and Wild, M.: Homogenization and Trend Analysis of the 1958-2016 In Situ Surface Solar Radiation Records in China, J. Climate, 31, 4529-4541, https://doi.org/10.1175/JCLI-D-17-0891.1, 2018.

Zeng, Z., Wang, Z., Gui, K., Yan, X., Gao, M., Luo, M., Geng, H., Liao, T., Li, X., An, J., Liu, H., He, C., Ning, G., and Yang, Y.: Daily Global Solar Radiation in China Estimated From High-Density Meteorological Observations: A Random Forest Model Framework, Earth Space Sci., 7, e2019EA001058, https://doi.org/10.1029/2019EA001058, 2020.

Zhou, C., Wang, J., Dai, A., and Thorne, P. W.: A New Approach to Homogenize Global Subdaily Radiosonde Temperature Data from 1958 to 2018, J. Climate, 34, 1163-1183, https://doi.org/10.1175/JCLI-D-20-0352.1, 2021.

Zhu, C., Wang, B., and Qian, W.: Why do dust storms decrease in northern China concurrently with the recent global warming?, Geophys. Res. Lett., 35, L18702, https://doi.org/10.1029/2008GL034886, 2008. 